\section{Avaliação da Atividade Secretora, Proliferação Celular e Expressão da Proteína p27 em Tumores Hipofisários}

\begin{abstract}
RESUMO
A finalidade deste estudo fol avaliar a atividade secretora, proliferação celular e inibição do ciclo celular das neoplasias hipofisárias. Os tecidos foram obtidos de 13 pacientes incluindo acromegalia $(n=5)$, adenomas não-secretores $(n=4)$, hiperprolactinemia $(n=3)$ e doença de Cushing $(n=1)$. Os espécimes foram examinados por técnica imuno-histoquímica com anticorpos anti-ACTH, anti-TSH, anti-LH, anti-FSH, anti-PRL, anti-hGH, anti-MIB-1 (análise da proliferação celular) e anti-p27 (análise da inibição do ciclo celular). A expressão imuno-histoquimica quanto à atividade secretora nos tumores hipofisários demonstrou que todos produziam mais que um hormônio. As células positivas para o marcador de proliferação celular MIB-1 mostraram-se presentes em aproximadamente $46 \%$ dos casos. A maior taxa proliferativa foi encontrada nos tumores com quadro clínico de acromegalia ( $80 \%$ dos casos). A taxa de positividade para a proteína p27 foi de aproximadamente $38 \%$, sendo, em média, maior no tumor responsável pela doença de Cushing. Esses resultados demonstram que os adenomas multisecretores são relativamente comuns. Os índices de proliferação celular baixos e os niveis de p27 próximos àqueles observados em tecidos normais expressam o baixo nivel de proliferação celular destes tumores. (Arq Bras Endocrinol Metab 2000;44/5: 397-404)
\end{abstract}

Unitermos: MIB-1; p27; Tumores hipofisários; Marcadores nucleares; Imunohistoquímica; Atividade secretora; Proliferação celular

\section{artigo original}

Disciplinas de Endocrinologia e Neurocirurgia da Faculdade de Medicina do Triângulo Mineiro

(FMTM), Uberaba, MG.

\begin{abstract}
The aim of this study was to evaluate the secretory activity, cell proliferation and inhibition of the cell cycle of pituitary neoplasm. Tissues were obtained from 13 patients presenting with acromegaly $(n=5)$, non-secreting adenomas $(n=4)$, hyperprolactinemia $(n=3)$ and Cushing's disease $(n=1)$. Specimens were examined by an immunohistochemical technique using anti-ACTH, anti-TSH, anti-LH, anti-FSH, anti-PRL, anti-hGH, antiMIB-1 (analysis of cell proliferation) and anti-p27 (analysis of cell cycle inhibition) antibodies. Regarding secretory activity all tumors produced more than one hormone. Cells positive for MIB-1 were present in approximately $46 \%$ of the cases. The highest incidence of proliferation was found in those presenting acromegaly ( $80 \%$ of the cases). Expression of the p27 protein was positive in approximately $38 \%$, being on an average, highest in Cushing's disease. These results demonstrate the presence of multisecretory pituitary adenomas, a relative common finding. The relatively low cell proliferation indexes and the near normal tissue levels of p27 confirm that these tumors grow at a rather slow rate. (Arq Bras Endocrinol Metab 2000;44/5: 397-404)
\end{abstract}

Keywords: MIB-1; p27; Pituitary adenomas; Celular markers; Immunohistochemistry; Secretory activity; Celular proliferation

\author{
Marcus Aurelho de Lima \\ Jacqueline Fonseca Rios \\ Lilia Beatriz Olipeiva \\ Maria Eliza Machado \\ Leopoldo P. Araújo \\ Maria de Fátima Borges
}

Recebido em 03/01/00

Revisado em 23/05/00 Aceito em 04/07/00 
A ADENO-HIPÓFISE É FORMADA POR CÉLULAS acidófilas, basófilas e cromófobas. As células acidófilas são somatotrofos (produzem GH) e lactotrofos (prolactina), as basófilas produzem hormônio adrenocorticotrófico $(\mathrm{ACTH})$, tirotrófico (TSH) e gonadotróficos ( $\mathrm{FSH}$ e LH) (1), enquanto as cromófobas, anteriormente relacionadas a adenomas não-secretores, são hoje consideradas também produtoras de hormônios $(2,3)$.

No desenvolvimento embriológico, o processo de diferenciação das células adeno-hipofisárias segue um padrão altamente específico. É proposto que haja uma célula tronco adeno-hipofisária que dá origem às células corticotróficas, gonadotróficas e a uma outra célula tronco, somatotrófica. Esta, por sua vez, origina os somatotrofos, tirotrofos e mamossomatotrofos, que dão origem aos lactotrofos. Esta seqüência é complexa e envolve várias proteínas reguladoras de transcrição identificadas na adeno-hipófise, que têm sido implicadas como elementos-chave na definição de fenótipos e na expressão de genes de regulação hormonal (4).

Os adenomas hipofisários são neoplasias benignas compostas de células adeno-hipofisárias (2) e são derivados dessas linhagens celulares (1), sendo os mais freqüentes os cromófobos, seguidos dos acidófilos e basófilos (5). Estes tumores são os mais comuns da região selar, representando 10 a $20 \%$ dos tumores intracranianos removidos cirurgicamente (6). As técnicas modernas de imagem e análise bioquímica da atividade hormonal sugerem que os adenomas hipofisários são comuns, ocorrendo em aproximadamente $20 \%$ da população geral (2), apesar de serem assintomáticos na maioria e diagnosticados post-mortem.

Estas neoplasias são consideradas proliferações clonais e exibem grande variedade de sintomas relacionados a distúrbios funcionais ou, também, proliferativos. A produção hormonal inapropriada pode levar a síndromes clínicas como acromegalia, doença de Cushing e hiperprolactinemia (2). Outros adenomas têm alta taxa de crescimento, causando sintomas de massa intracraniana ou distúrbios visuais $(2,7)$. Entretanto, há, ainda, adenomas hipofisários inativos (nãosecretores) que, embora secretem um ou mais hormônios hipofisários, não há aumento da sua concentração sangüínea (8). Sendo a atividade hormonal a base do diagnóstico e da terapêutica desses tumores, é de fundamental importância o estudo da sua atividade secretora através de técnicas histoquímicas $(2,6,8)$.

$\mathrm{O}$ desenvolvimento de técnicas de detecção imunológica de antígenos em tecidos revolucionou o estudo dos adenomas hipofisários $(2,5,9)$. A imunohistoquímica tem revelado fenótipos moleculares nãosuspeitos, o que determina grandes mudanças na cate- goria neurodiagnóstica de certos tumores cerebrais. Esta técnica tem sido reservada para o uso clínico regular no diagnóstico de massas intracranianas (10). Os prolactinomas são o tipo mais comum de adenomas (6) e os produtores de $\mathrm{GH}$ e $\mathrm{ACTH}$ representam 10 a $15 \%$, enquanto os produtores de TSH são raros (2). Recentemente, com o vasto uso da imuno-histoquímica, a prevalência de adenomas pluri-hormonais está crescendo gradualmente $(7,9)$.

Apesar de não haver associação entre a taxa proliferativa e a recidiva dos adénomas pituitários (11), o prognóstico destes tumores parece estar relacionado com a proliferação celular.

O estudo da proliferação celular em tumores hipofisários vem sendo muito desenvolvido, particularmente após a introdução de técnicas modernas como os marcadores nucleares do tipo do MIB-1 (10-12). Os adenomas hipofisários invasivos têm maior atividade proliferativa que os não-invasivos $(13,14)$; os invasivos são, geralmente, os adenomas tireotróficos e adenomas corticotróficos não-secretores $(15,16)$.

Um outro marcador, a proteína p27 é inibidora do ciclo celular em Gl $(17,18)$ e os seus níveis são maiores em células quiescentes do que naquelas em proliferação (19). A p27 age através da inibição do complexo quinases ciclina-dependentes (CDK), incluindo os complexos ciclina $\mathrm{D}$ e $\mathrm{E}$, envolvidos na progressão do ciclo celular (20). Nas células neoplásicas de hipófise há diminuição da expressão de p27 quando se compara com hipófises normais (19,21-23). O papel da p27 como um possivel gene supressor de tumor tem sido apontado por vários investigadores $(19,23,24)$. As células produtoras de GH e ACTH têm menores porcentagens de p27, enquanto os lactotrofos têm maior porcentagem desta proteína (18).

Com o objetivo de melhor caracterizar os possíveis mecanismos envolvidos na progressão dos tumores pituitários, estudamos por técnica de imunohistoquímica a atividade secretora e marcadores de proliferação e inibição de crescimento celulares em macroadenomas hipofisários diagnosticados em nosso serviço durante o período compreendido entre os anos de 1990 e 1997.

\section{MATERIAL E MÉTODOS}

\section{Seleçāo de casos}

Foram examinadas 13 neoplasias hipofisárias que clinicamente se apresentaram como acromegalia $(n=5)$, adenomas não-secretores $(n=4)$, prolactinomas $(n=3)$ e doença de Cushing ( $n=1)$, diagnosticados entre 1990 e 1997. Todos os tumores eram macroadenomas. 
Tabela 1. Manifestação clínica dos casos estudados

\begin{tabular}{cccl}
\hline & Idade & Sexo & Manifestação clínica \\
\hline 1 & 38 & $F$ & Acromegalia, amenorréia, cefaléia e diminuição da acuidade visual \\
2 & 44 & $F$ & Acromegalia, amenorréia, cefaléia e galactorréia \\
3 & 39 & $F$ & Acromegalia, galactorréia e diminuição da visão \\
4 & 36 & $F$ & Acromegalia, cefaléia e amenorréia \\
5 & 37 & M & Acromegalia, diabetes e impotência sexual \\
6 & 30 & $F$ & Cefaléia \\
7 & 31 & M & Cefaléia, tonturas e escurecimento visual \\
8 & 52 & M & Diplopia, cefaléia e diminuição visual \\
9 & 66 & M & Cefaléia, vômitos, ptose palpebral e oftalmoplegla \\
10 & 25 & $F$ & Galactorrêia e amenorréia \\
11 & 50 & M & Diminuição da visão e cefaléia \\
12 & 44 & $F$ & Escotoma hemianóptico direito \\
13 & 33 & $F$ & Síndrome de Cushing, amenorréia, hipertensão arterial e obesidade \\
\hline
\end{tabular}

O material foi obtido de hipofisectomia transesfenoidal de pacientes com idades entre 25 e 66 anos: oito eram mulheres e cinco, homens. Previamente à cirurgia, os pacientes submeteram-se à avaliação clínica, neuro-oftalmológica e hormonal, que consistiu inicialmente de dosagens hormonais basais de $\mathrm{GH}$, prolactina, $\mathrm{LH}, \mathrm{FSH}, \mathrm{T}_{4}$ livre e estradiol $\left(\mathrm{E}_{2}\right)$ nas mulheres e testosterona (testo) nos homens. Posteriormente, e dentro do contexto clínico, os pacientes eram submetidos ao teste combinado IV de reserva hipofisária utilizando insulina $(0,1 \mathrm{U} / \mathrm{kg})$ para estímu-

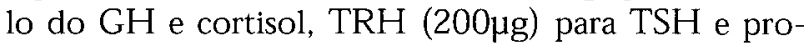

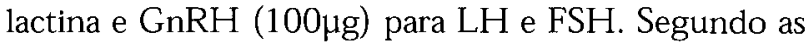
deficiências observadas na avaliação, era instituída terapia substitutiva. Além disto, os pacientes eram submetidos a campimetria e à tomografia computadorizada (TC) ou ressonância magnética.

As dosagens hormonais foram feitas por quimioluminescência automatizada usando um sistema Immulite e através de estojos comerciais obtidos de DPC (Diagnostic Products Corporation, LA, Califórnia).

O diagnóstico das neoplasias pituitárias fundamentou-se na morfologia histopatológica clássica conhecida (2) e correlacionada com a avaliação clínica e laboratorial efetuadas previamente.

\section{Técnica Imuno-histoquímica}

Para análise imuno-histoquímica, utilizaram-se os anticorpos monoclonais anti-ACTH, anti-TSH, antiLH e anti-FSH (Dako Corporation, Glostrup, Dinamarca) em diluição de 1:100 e os anticorpos policlonais rabbit anti-prolactin e anti-hGH (Dako Corporation, Glostrup, Dinamarca) em diluição de 1:400. O anticorpo monoclonal MIB-1 (anti-Ki 67, Dako Corporation, Glostrup, Dinamarca) em diluição de 1:50 e o anticorpo anti-p27 (Santa Cruz Biotecnology) em diluição de 1:50.
Os tecidos foram fixados em formalina a $3,7 \%$, incluídos em parafina e cortados à espessura de $4 \mu \mathrm{m}$. Os cortes foram desparafinizados, hidratados e tiveram pré-tratamento com solução tampão de citrato de sódio $0,01 \mathrm{M}, \mathrm{pH}=6,0 \mathrm{em}$ forno microondas durante 2 ciclos de $9 \mathrm{~min}$ em potência máxima $(900 \mathrm{~W})$. A cada ciclo, completava-se o volume com tampão citrato de sódio para que os cortes não secassem. Em seguida, as lâminas eram mantidas por 20 minutos no interior do forno desligado. Posteriormente, enxaguadas em água corrente e colocadas em solução de água oxigenada a 3\% por 15 min. Novamente, foram enxaguadas em água corrente e colocadas em solução PBS $(\mathrm{pH}=7,4)$ por 10 min. Os cortes eram incubados com o anticorpo primário nas diluições já citadas durante 22 horas, a $4^{\circ} \mathrm{C}$. Posteriormente, utilizou-se o sistema de detecção avidina-biotina (KO 675; Dako Corporation, Glostrup, Dinamarca). A revelação foi feita utilizando-se como cromógeno 3-amino-9-ethyl-carbazol (AEC-A-5754; Sigma, St. Louis, MO, EUA). A contracoloração dos cortes foi feita com hematoxilina de Mayer. Como controle positivo, utilizou-se secção de hipófise normal para os anticorpos anti-ACTH, anti-TSH, anti-LH, anti-FSH, anti-prolactina e anti-hGH; corte de amígdala normal para o MIB-1 e secção de intestino delgado normal para a proteína $\mathrm{p} 27$. Como controle negativo, usou-se o próprio caso sem o anticorpo primário.

\section{Contagem de Células}

\section{Atividade secretora}

Para avaliação da taxa de células secretoras de prolactina, GH, ACTH, TSH, LH ou FSH foi analisada a expressão protéica em células de toda a área de corte. Cada célula corada foi considerada positiva independentemente da intensidade. A positividade foi classificada de acordo com a porcentagem de células positivas 
em todo o campo tumoral, variando desde $<10 \%(+)$, 10 a $50 \%(++), 50$ a $75 \%(+++)$ e $>75 \%(++++)$.

\section{Proliferação celular}

Para avaliação da taxa de células positivas para MIB-1, foram contados pelo menos 1.000 núcleos em diferentes áreas selecionadas, de acordo com a maior positividade. $O$ índice de proliferação celular corresponde ao número de células tumorais positivas / 1.000 células tumorais. Cada núcleo corado foi considerado positivo independente da intensidade. A quantificação foi feita por dois observadores em campos microscópicos de luz de 400x.

\section{Inibição do ciclo celular}

Para avaliação do número de células p27 positivas, foram contadas 1.000 células em diferentes áreas selecionadas de acordo com a maior positividade. Cada célula corada foi considerada positiva independente da intensidade. A quantificação foi feita por dois observadores em campos microscópicos de luz de 400x.

\section{RESULTADOS}

\section{Atividade Secretora em Tumores Hipofisários}

Os pacientes portadores de acromegalia, além do quadro clínico característico e exames de imagens compatíveis com macroadenoma, tinham niveis basais elevados de $\mathrm{GH}$ que variaram de 34,6 a $274 \mathrm{ng} / \mathrm{ml}$ e deficiência dos demais setores. Um deles apresentava níveis basais de prolactina de $410 \mathrm{ng} / \mathrm{ml}$ que, após estímulo, foi para $900 \mathrm{ng} / \mathrm{ml}$.

Os pacientes com diagnóstico de macroprolactinoma tinham niveis basais de prolactina entre 186,6 e $942 \mathrm{ng} / \mathrm{ml}$ e que não responderam a estímulo.

Os pacientes com adenomas não secretores tinham niveis basais de $\mathrm{GH}$ normais e de prolactina menores que $50 \mathrm{ng} / \mathrm{ml}$ e panhipopituitarismo. Neste grupo houve predomínio de sinais neuro-oftalmológicos.

O único paciente com doença de Cushing tinha cortisol basal de $65 \mu \mathrm{g} / \mathrm{dl}$ não supressível com 2 e 8 mg de dexametasona, associado à hipotiroidismo.

Em relação aos tumores que causaram acromegalia, a positividade para o $\mathrm{GH}$ foi observada nos cinco casos, apresentando intensidade $\mathrm{de}++(\mathrm{n}=2),+++$ $(n=2)$ e $++++(n=1)$. Da mesma forma, a expressão foi positiva para PRL e LH em todos os casos, no entanto em baixa ou moderada intensidade. Para a PRL, houve um caso com intensidade + e 4 com ++ , enquanto para o LH, 3 casos foram + e 2 foram ++ . Houve positividade de + para o FSH e TSH, ocorrendo em um e 2 casos, respectivamente. Já para o $\mathrm{ACTH}$, não houve índice positivo em nenhum caso.

Foram analisados 4 adenomas hipofisários classificados clinicamente como não-secretores. A positividade para o $\mathrm{GH}$ ocorreu em todos os casos, variando de $++(n=3)$ a $+++(n=1)$ e para o ACTH em apenas um caso $(+++)$. A reação imuno-histoquímica foi negativa para os outros hormônios (PRL, TSH, FSH e LH) em todos os adenomas.

Nos três prolactinomas, a imunopositividade para PRL mostrou-se presente e elevada em 2 casos $(+++)$ e menor no outro $(++)$. Houve também positividade para o LH em 2 casos ( + ) e para o GH em um $(++)$. Esses tumores não apresentaram imuno-reatividade para TSH, ACTH ou FSH.

O tumor hipofisário que se apresentou clinicamente como doença de Cushing mostrou imunopositividade para ACTH e GH (+++). Não houve reatividade para os outros hormônios.

\section{MIB-1}

As taxas de células MIB-1 positivas nos diferentes tumores hipofisários são mostradas na tabela 2. Dos 5 tumores pituitários que cursaram com acromegalia, 4 apresentaram atividade proliferativa de 0,$1 ; 0,7 ; 1,3$ e $2 \%$.

Células MIB-1 positivas estiveram presentes em um dos 4 adenomas que se apresentaram clinicamente como não-secretores, com indice de $1 \%$. Apenas um dos 3 prolactinomas, mostrou taxa de proliferação celular de $0,1 \%$. O adenoma associado com doença de Cushing revelou-se negativo para MIB-1.

\section{p27}

A positividade para a proteína p27 nos tumores de hipófise é apresentada na tabela 3 . Em relação aos 5 tumores que cursaram com acromegalia, apenas um apresentou-se positivo para a p27, com taxa de $0,3 \%$.

Tabela 2. Taxa de células positivas para o marcador de proliferação celular MIB-1 em tumores hipofisários

\begin{tabular}{lccc}
\hline Diagnóstico Clínico $(n=14)$ & Média (\%) & Desvio padrão (\%o) & Variação \\
\hline Acromegalia $(n=5)$ & 0,84 & 0,75 & $0,13-2,00$ \\
Adenoma não-secretor $(n=4)$ & 0,26 & 0,45 & $0,00-1,06$ \\
Prolactinoma $(n=3)$ & 0,02 & 0,02 & $0,00-0,06$ \\
Doença de Cushing $(n=1)$ & 0,00 & 0,00 & 0,00 \\
\hline
\end{tabular}


Tabela 3. Taxa de células positivas para a p27 em tumores hipofisários

\begin{tabular}{lccc}
\hline Diagnóstico Clínico $(\mathrm{n}=14)$ & Média (\%o) & Desvio padrão (\%o) & Variação \\
\hline Acromegalia $(n=5)$ & 0,06 & 0,132 & $0,00-0,33$ \\
Adenoma não-secretor $(n=4)$ & 0,02 & 0,043 & $0,00-0,10$ \\
Prolactinoma $(n=3)$ & 0,15 & 0,111 & $0,00-0,26$ \\
Doença de Cushing $(n=1)$ & 0,33 & 0,000 & 0,33 \\
\hline
\end{tabular}

Apenas um dos 4 adenomas não-secretores, obteve indice de $0,1 \%$ de células p 27 positivas. Houve expressão de p27 em 2 dos 3 casos de prolactinoma, sendo de 0,2 e $0,26 \%$, respectivamente. O tumor classificado clinicamente como doença de Cushing foi positivo, com índice de $0,3 \%$.

\section{Correlação entre MIB-1 e p27}

Os adenomas associados com acromegalia apresentaram correlação inversamente proporcional para MIB-1 e p27, ou seja, todos os casos positivos para o MIB-1 foram negativos para $\mathrm{p} 27$, e vice versa, tendo havido predominância ( $80 \%$ dos casos) para a atividade proliferativa (MIB-1 positivo).

Metade dos adenomas não-secretores tiveram expressão negativa para o MIB-1 e p27. Nos outros 2 casos, um mostrou proliferação celular (MIB-1 positivo e p27 negativo) e o outro foi $\mathrm{p} 27$ positivo e MIB-1 negativo.

Em um dos prolactinomas não houve células positivas para MIB-1 ou p27; outro apresentou inibição da taxa de proliferação celular ( 27 positivo e MIB-1 negativo), e o terceiro apresentou expressão positiva para ambos os marcadores.

O caso de doença de Cushing foi positivo para a p27 e MIB-1 negativo, mostrando que nem todos os tumores produtores de ACTH têm alta taxa proliferativa.

\section{DISCUSSÃO}

A avaliação da atividade secretora nos tumores hipofisários demonstrou que todos produziam mais que um hormônio. Aa produção de dois ou mais hormônios é uma ocorrência comum nestes tumores $(2,5)$, sendo mais freqüente a secreção de PRL combinada com $\mathrm{GH}(1,2,5,7)$.

Os adenomas que cursaram com acromegalia tiveram expressão positiva para o $\mathrm{GH}$ em todos os casos estudados, associado à produção de PRL e LH. Isto acontece porque os adenomas somatotrofos são compostos por uma população de células plurihormonais, capazes de produzir GH, PRL e subunidade $\alpha-L H$ (2), contendo características de linhagens celulares acidófilas e basófilas (1). A imuno-histoquímica mostrou também secreção de TSH e FSH em 40 e $20 \%$ dos casos, respectivamente. Este achado mostrou que outras combinações hormonais podem também ocorrer nos adenomas hipofisários (7); além disso, células normais podem ter contaminado a área sob investigação, o que também poderia explicar a positividade imuno-histoquímica para vários hormônios.

Já nos adenomas classificados clinicamente como não-secretores, a análise imuno-histoquímica apresentou positividade para $\mathrm{GH}$ em todos os tumores (de moderada a alta intensidade). Houve também secreção de $\mathrm{ACTH}$ em $25 \%$ dos casos, com alta expressão. De acordo com a literatura, os adenomas não-secretores produzem com maior freqüência gonadotrofinas, subunidades $\alpha$ e $\beta$ e prolactina (25). No entanto, todos os tipos de adenomas (somatotrofos, lactotrofos, tireotrofos, corticotrofos e gonadotrofos) também podem ser silenciosos (2). Isto mostra que esses tumores, assim classificados, na verdade, têm tido sua incidência muito diminuída desde o advento da imuno-histoquímica $(3,8)$. Assim, eles se comportam como adenomas somatotróficos e corticotróficos silenciosos, podendo haver níveis séricos elevados (mas inativos) ou normais de GH ou ACTH (2).

$O$ estudo da secreção nos prolactinomas revelou elevada expressão de PRL em dois terços dos casos. Houve secreção associada também nos dois terços dos tumores para o LH, com baixa intensidade, e em $33 \%$ dos casos para o GH de moderada intensidade. Isto evidencia a presença de adenomas hipofisários multisecretores, um achado relativamente comum (5). Sabendo-se que na maioria desses tumores a manifestação é de apenas uma síndrome ou outra (2), nestes casos houve predominância da síndrome de hiperprolactinemia. Não houve correlação entre a positividade de atividade secretora para prolactina e seus níveis séricos basais, que se apresentaram muito altos e semelhantes em 2 casos, de 942 e $634 \mathrm{ng} / \mathrm{ml}$ e cujas positividades foram ++ e +++, respectivamente. No terceiro caso, com positividade +++ , o nível basal de prolactina foi de $186,6 \mathrm{ng} / \mathrm{ml}$.

A atividade secretora no adenoma que se apresentou como doença de Cushing, evidenciou alta expressão positiva para o $\mathrm{ACTH}$ e $\mathrm{GH}$. Adenomas 
hipofisários que secretam ACTH estão raramente associados com produção de outros hormônios (9) como a subunidade $\alpha$ de hormônios glicoprotéicos. Não foi encontrada na literatura expressão combinada de $\mathrm{ACTH}$ e GH na doença de Cushing. Provavelmente, em vista da ausência de manifestações, apesar da alta expressão para $\mathrm{GH}$, este hormônio deve ser bioquimicamente inativo.

Quanto à proliferação celular, estudada através do marcador nuclear MIB-1, mostrou-se presente em aproximadamente $46 \%$ dos casos, com índices bastante baixos que variaram de 0,1 a $2 \%$, quando se compara com taxas observadas em neoplasias de órgãos como mama, pulmões, estômago e cólon cujos índices variam de 28,3 a $57,6 \%$ (26). Este dado corrobora relatos prévios mostrando que os adenomas hipofisários são lesões de crescimento relativamente lento (12). A maior taxa proliferativa nos tumores foi encontrada naqueles que cursaram com acromegalia, em $80 \%$ dos casos. No restante, observamos expressão positiva para o MIB-1 em 25\% dos casos de adenomas não-secretores e $33 \%$ dos prolactinomas. Estas diferenças podem ser atribuídas à presença de invasão extra-selar ou a recorrência do tumor, visto que os adenomas invasivos têm maior taxa proliferativa que os não-invasivos (27).

Em nosso estudo, dos seis casos positivos para MIB-1, dois deles apresentaram invasão extra-selar, havendo recorrência em apenas um. O caso que apresentou invasão e recorrência era um prolactinoma, que tinha nível sérico elevado de prolactina $(634 \mathrm{ng} / \mathrm{ml})$. O tumor no qual se observou apenas invasão era nãosecretor e media $1,84 \times 1,84 \mathrm{~cm}$ à tomografia computadorizada (TC). Foi demonstrado que adenomas recorrentes têm taxa proliferativa significativamente mais alta que os tumores iniciais (28). Além disso, adenomas pequenos têm potencial de crescimento limitado quando comparados com macroadenomas invasivos (17). O único caso que se apresentou clinicamente como doença de Cushing mostrou expressão negativa para o MIB-1, fato não esperado, visto que em outros estudos os tumores silenciosos produtores de ACTH apresentam maior taxa de invasão quando comparados a outros tumores secretores $(15,16)$ e maiores índices de positividade para o MIB-1 (29).

Em relação à expressão da proteína p27, inibidora do ciclo celular, a taxa de positividade foi de aproximadamente $38 \%$ nos adenomas analisados, cuja expressão variou de 0,1 a $0,3 \%$. Há relatos de que a expressão de p27 é menor em adenomas e carcinomas hipofisários quando comparada a tecidos normais $(19,21,30,31)$. Entretanto, outros resultados não mostram diminuição nos níveis de p27 em tumores hipofisários, o que explicaria o fato desses adenomas terem baixo nivel de proliferação celular (14). Dos 5 tumores que cursaram com acromegalia, um foi posi-

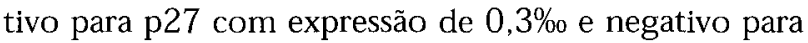
MIB-1, e nos adenomas não-secretores a positividade para p27 ocorreu em $25 \%$ em $0,1 \%$ das células. Nos prolactinomas, dois dos três tumores tiveram expressão de p27, 0,2 e 0,26\% das células, e o tumor produtor de ACTH, manifestando-se com doença de Cushing, apresentou índice positivo de $0,3 \%$, corroborando a negatividade para MIB-1 e ao contrário do observado na literatura, onde os adenomas secretores de ACTH tiveram significante diminuição da expressão de $\mathrm{p} 27$, comparados aos outros tipos de adenomas $(20,32,33)$. Além disso, alguns mecanismos de inativação da proteína p27, ainda obscuros e não relacionados com mutações ou deleções no seu gene, devem estar associados a subtipos histológicos mais agressivos de tumores secretores de ACTH (33), visto que os baixos niveis de expressão de $\mathrm{p} 27$ em corticotrofos de hipófise normal praticamente desapareceram em adenomas corticotróficos (20).

Dos oito tumores negativos para $\mathrm{p} 27$, dois apresentaram recidiva, sendo ambos adenomas não-secretores cujos tamanhos à TC foram $3 \times 2,5 \mathrm{~cm}$ e $4,6 \times 4 \mathrm{~cm}$. Outros dois apresentaram invasão, de tal forma que um deles apresentou-se como não-secretor, medindo $1,84 \times 1,84 \mathrm{~cm}$, e o outro era um prolactinoma produtor de altos níveis de prolactina $(942 \mathrm{ng} / \mathrm{ml})$, cuja medida à TC era de $2,14 \times 1,63 \mathrm{~cm}$. Em células de hipófise normal, há distribuição diferencial de p27, sendo maior em lactotrofos, gonadotrofos e tirotrofos e menor em somatotrofos e corticotrofos. A expressão menor de p27 em células hipofisárias é provavelmente influenciada por hormônios hipotalâmicos, esteróides e vários outros fatores de crescimento (18).

Foi demonstrado em nosso trabalho que os adenomas de hipófise têm característica pluri-hormonal e baixa atividade proliferativa. Concluímos que o uso da imuno-histoquímica e de marcadores de proliferação e inibição do ciclo celular podem auxiliar e influenciar no diagnóstico, na terapêutica e no prognóstico dos adenomas de hipófise, visto que há correlação entre os tipos de hormônios secretados e a taxa de proliferação celular com a invasão tumoral e recidiva após tratamento.

\section{REFERÊNCIAS}

1. Matsuno A, Sasaki T, Mochizuki T, Fujimaki T, Sanno N, Osamura $\mathrm{Y}$, et al. A case of pituitary somatotroph adenoma with concomitant secretion of growth hormone, prolactin, and adrenocorticotropic hormone- 
an adenoma derived from primordial stem cell, studied by immunohistochemistry, in situ hibridization, and cell culture. Acta Neurochir 1996; 138:1002-7.

2. Asa SL. Atias of Tumor Pathology. Tumors of the Pituitary Gland. $1^{\text {st }}$ ed. Washington: Armed Forces Instifute of Pathology, 1998; 3: 47-150.

3. Chao JC, Reyes CV, Chinoy M. Null cell adenoma of the pituitary gland. South Med J 1991;84:1239-42.

4. Asa SL, Ezzat S. The cytogenesis and pathogenesis of pituitary adenomas. Endocr Rev 1998: 19:798-827.

5. Heitz PU, Iversen $\mathrm{OH}$, Nogales F, Sasano N, Seifert $G$, Underwood JCE, ef al. Tumors of the Pituitary Gland Curr Topics Pathol 1988:77:286-9.

6. Kontogeorgos G, Kovacs K, Horvath E, Scheithauer BW Multiple adenomas of the human pituitary. J Neurosurg 1991;74: 243-7.

7. Kovacs K. Pathology of growth hormone excess. Pathol Res Pract 1998; 183:565-8.

8. Croue A, Beldent V, Rousselet MC, Guy G, Rohmer V, Bigorgne $\mathrm{JC}$, et al. Contribution of immunohistochemistry, electron microscopy, and cell culture to the characterization of nonfunctioning pituitary adenomas: a study of 40 cases. Hum Pathol 1992;23:1332-9.

9. Felix I, Asa SL, Kovaks K, Horvath E. Changes in hormone production of a recurrent silent corticotroph adenoma of the pituitary: a histologic, immunohistochemical, ultrastructural, and tissue culture study. Hum Pathol 1991:21:719-21.

10. Mckeever PE. Insights about brain tumors gained through immunohistochemistry and in situ hybridization of nuclear and phenotypic markers. J Histochem Cytochem 1998:46:585-94.

11. Yonezawa K,Tamaki N, Kokunai T. Clinical features and growth fractions of pituitary adenomas. Surg Neurol 1997:48:494-500.

12. Thapar K, Kovaks K, Scheithauer BW, Stefaneanu L, Horvath $E$, Pernicone $P$, et al. Proliferative activity and invasiveness among pituitary adenomas and carcinomas: an analysis using the MIB-1 antibody. Neurosurgery 1996;38:99-107.

13. Katznelson L, Bogan J, Trob J, Schoenfeld DA, HedleyWhite ET, Hsu DW, et at. Biochemical assessment of Cushing's disease in patients with corticotroph macroadenomas. J Clin Endocrinol Metab 1998;83:1619-23.

14. Pernicone P, Scheithauer BW, Sebo T, Kovaks K, Horvath $E$, Young WF, et al. Pituitary carcinoma. Cancer 1997:79:804-12.

15. Sautner D, Saeger W. Invasiviness of pituitary adenomas. Pathol Res Pract 1991:187:632-6.

16. Scheithauer BW, Kovacs KT, Laws ER Jr, Randall RV. Pathology of invasive pituitary tumors with special reference to functional classification. J Neurosurg 1986:65:733-44.
17. Calle-Rodrigue RDP, Giannini C, Scheithauer BW, Lloyd RV, Wollan PC, Kovaks $K$, et al. Prolactinomas in male and female patients: a comparative clinicopathologic study. Mayo Clin Proc 1998; 73:1046-52.

18. Qian X, Jin L, Grande JP. Lloyd RV. Transforming growth factor $\beta$ and $p-27$ expression in pltuitary cells. Endocrinology 1996; 137:3051-60

19. Jin L, Qian X, Kulig E, Sanno N, Scheithauer BW, Kovaks K, et al. Transforming growth factor- $\beta$, transforming growth factor- $\beta$ receptor $\|$, and $p-27 k i p l$ expression in nontumorous and neoplastic human pituitaries. Am J Pathol 1997; 151:509-19.

20. Lidhar K, Korbonits M, Jordan S, Khalimova Z, Kaltsas G, Lu $X$, et al. Low expression of the cell cycle inhibitor p27kipl in normal corticotroph cells, corticotroph tumors, and malignant pltuitary tumors. J Clin Endocrinol Metab 1999;84:3823-30.

21. Lloyd RV, Jin L, Qian X, Kulig E. Aberrant p27kipl expression in endocrine and other tumors. Am J Pathol $1997 ; 150: 400-7$

22. Takeuchi S, Koeffler HP, Hinton DR, Miyoahi I, Melmed S, Shimon I. Mutation and expression analysis of the cyclindependent kinase inhibitor gene p27/kipl in pituitary tumors. J Endocrinol 1998; 157:337-41.

23. Bamberger CM, Fehn M, Bamberger AM, Beil FU, Saeger W. Schulte HM. Strongly reduced expression levels of the cell cycle inhibitor p27 in pituitary tumors. Clin Exper Pathol 1998;46(5-6):359.

24. Qian X, Jin L, Kulig E، Lloyd RV. DNA Methylation regulates p27 kipl expression in rodent pituitary cell lines. Am J Pathol 1998; 153:1475-82.

25. Liuzzi A, Tassi V, Pirro MT, Zingrillo M, Ghiggi MR, Chiodini l, et al. Nonfunctioning adenomas of the pituitary. Metabolism 1996:45:80-2.

26. Katoh R, Bray CE, Suzuki K, Komiyama A, Hemmi A Kawaoi A, et al. Growth activity in hyperplastic and neoplastic human thyroid determined by an immunohistochemical staining procedure using monoclonal antibody MIB-1. Hum Pathol 1995:26:139-46.

27. Blevins LS Jr, Berity DK, Allen G. Aggressive pituitary tumors. Oncology 1998;12:1307-12.

28. Abe T, Sanno N, Osamura YR, Matsumoto K. Proliferative potential in pituitary adenomas: measurement by monoclonal Intibody MIB-1. Acta Neurocir 1997;139:613-8.

29. Mastronardi L, Guiducci A, Spera C, Puzzilli F, Liberati F, Maira $G$. Ki-67 labelling index and invasiveness among anterior pituitary adenomas: analysis of 103 cases using the monoclonal antibody. J Clin Pathol 1999;52:107-11.

30. Lloyd RV, Jin L, Kulig E, Oka H, Qian X, Scheithauer BW. Role of cell cycle proteins during pituitary tumor development. Endocr Pathol 1998;9:408

31. Lloyd RV, Jin L, Kulig E, Oka H, Qian X, Scheithauer BW. Recent advances in pituitary pathology. Endocr Pathol 1998:9:407. 
32. Komatsubara $K$, Sanno N, Teramoto A, Ito $Y$, Osamura RY. Immunohistochemical expression of p27 protein in venous types of human pitultary adenomas. Endocr Pathol 1998:4:399.

33. Dahia PL, Aguiar RC, Honegger J, Fahlbush R, Jordan S, Lowe DG, et al. Mutation and expression analysis of the p27/kipl gene in corticotrophin-secreting tumours. Oncogene 1998; 16:69-76.

\section{Endereço para correspondência:}

Marcus Aurelho de Lima

Disciplina de Endocrinologia, Hospital Escola - FMTM

Rua Getúlio Guarita، 130

38025-440 Uberaba, MG

Fax: 034-312 6640

e-mail: lima@mednet.com.br 